THESMAZON

- measuring a
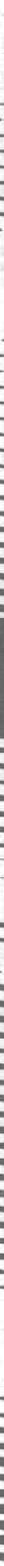

U.S. DEPARTMENT OF THE INTERIOR GEOLOGICAL SURVEY 


\section{- THE MAZON}

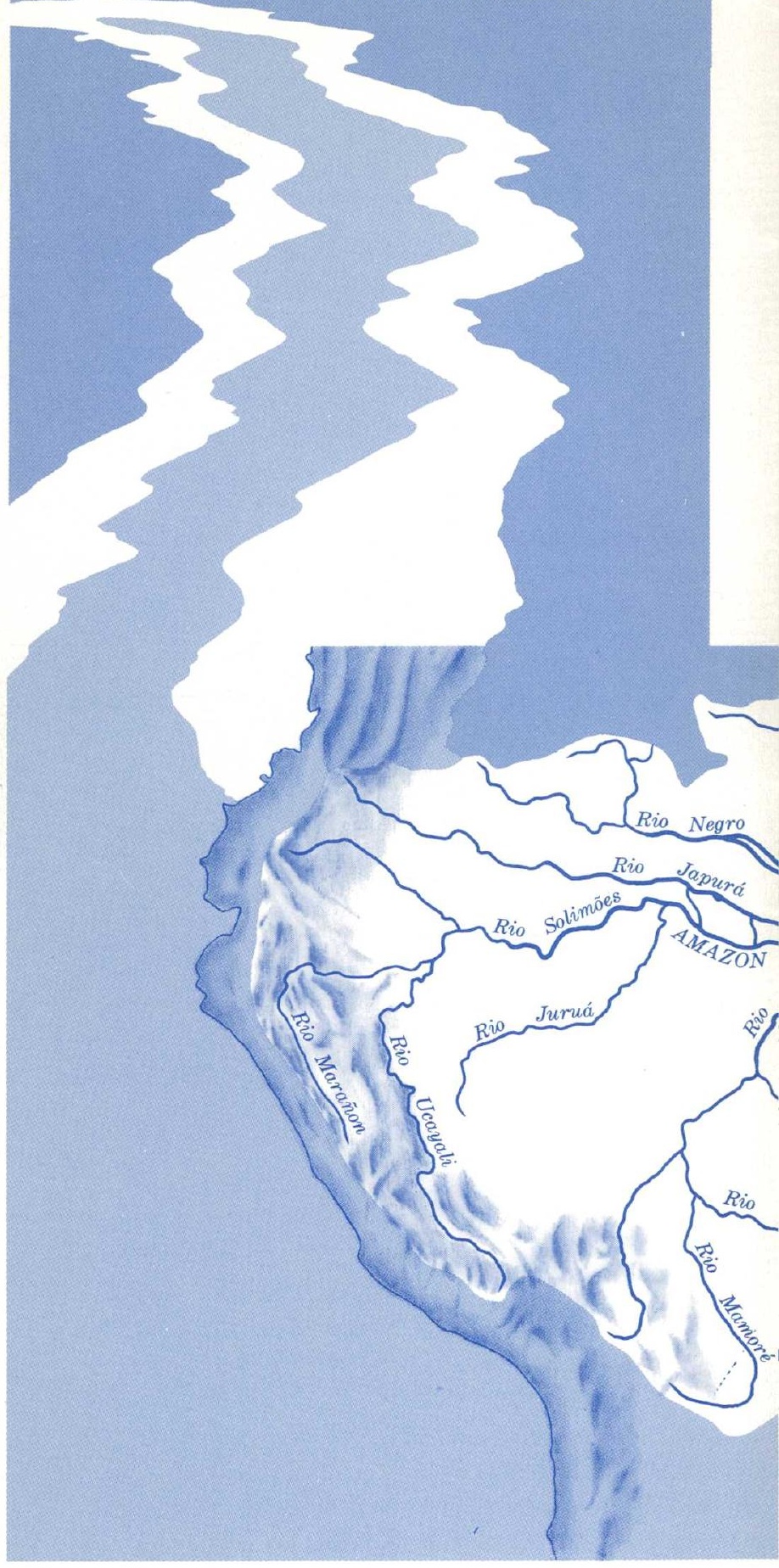


The Amazon, the world's largest river, discharges enough water into the sea each day to provide fresh water to the City of New York for over 9 years. Its flow accounts for about 15 percent of all the fresh water discharged into the oceans by all the rivers of the world. By comparison, the Amazon's flow is over 4 times that of the Congo River, the world's second largest river. And it is 10 times that of the Mississippi, the largest river on the North American Continent.

Man has been fascinated by the Amazon-its huge size, challenging frontier, and natural beauty-since it was discovered in 1500 by the Spanish explorer Vicente Yáñez Pinzón. Since the 16th century, many other explorers (among them Theodore Roosevelt) have traveled in the Amazon Basin, but until recently

The Amazon River is fed by more than 200 tributaries, some of which are more than 1000 miles long.

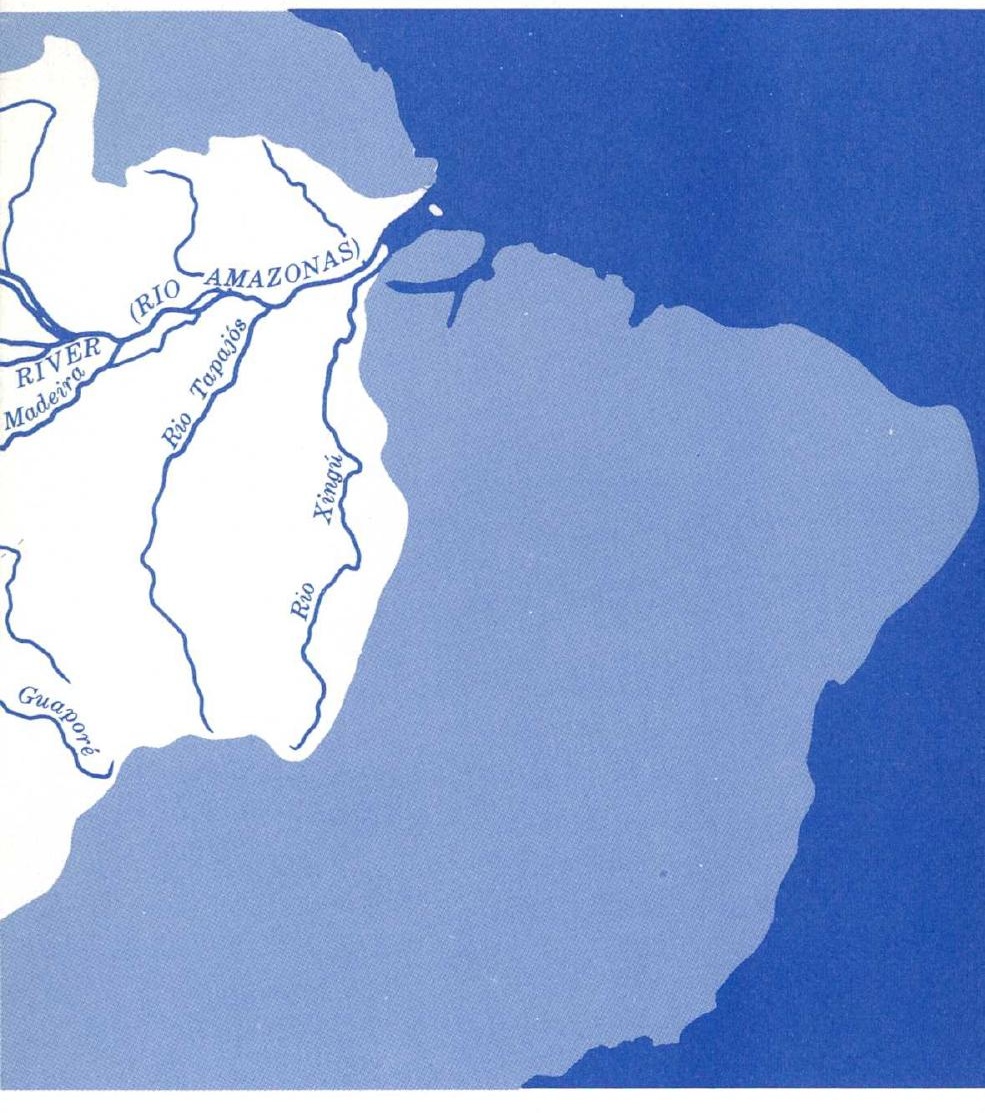


there has been only a small amount of water resource data gathered about this huge South American waterway.

In 1963 and again in 1964, in cooperation with the University of Brazil and the Brazilian Navy, a team of U.S. Geological Survey scientists conducted hydrologic investigations on the Amazon to measure its flow, its physical characteristics, and its chemical composition.

The Amazon begins its eastward flow from a chain

\section{THE BASIN} of glacier-fed lakes high in the Andes Mountains in central Peru. Lago Lauricocha, a small mountain lake, is the actual source. The headwaters are small, rapidly flowing mountain streams that finally join in a mainstream. Emerging from the eastern Andean foothills the river sweeps through the world's largest tropical rain forest which ranges from 500 to 600 miles wide, where the lowlands meet the Andes, to 200 miles wide along the Atlantic Coast.

Enroute to the sea, the Amazon receives drainage from about 2.3 million square miles of land, an area close to three-quarters the size of the conterminous United States. Over 200 tributaries, some more than 1,000 miles long, empty into the Amazon.

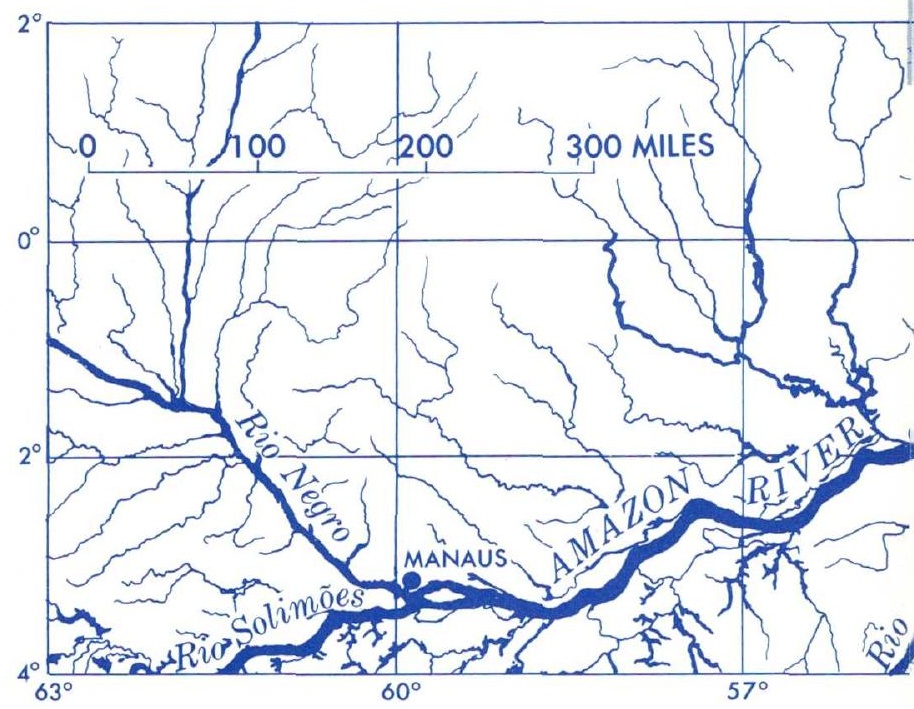


Geologists have theorized that millions of years ago a large fresh-water lake covered the entire area of the present drainage basin. A general uplift occurred and now a massive rain forest covers the area formerly occupied by that ancient lake. The wet tropical climate continually refurbishes the forest's growth. Sometimes described as the world's most spectacular greenhouse, the forest contains as many as 3,000 plant species per square mile. Except along the river, however, the forest has little of the undergrowth that is associated with jungle terrain.

The soil in the basin has been so thoroughly washed of mineral content by heavy rain that it is not sufficiently fertile for most agricultural crops. Only along the flood plains is the soil rich enough for agricultural development.

Contrary to popular assumption, the climate in the area is not one of only exceedingly high temperatures. Actually the average temperature is about $86^{\circ} \mathrm{F}$, with a range of $4^{\circ} \mathrm{F}$ between the warmest and coldest months. The humidity is high, generally about 85 percent even during the driest season. Rainfall ranges from 50 to 120 inches per year and averages about 80 inches over the entire basin with the heaviest rainfall occurring from January to June. The heavy rainfall over such a large area accounts for the Amazon's high rate of flow.

The Amazon investigations were conducted along the lower 900-mile stretch of the river.

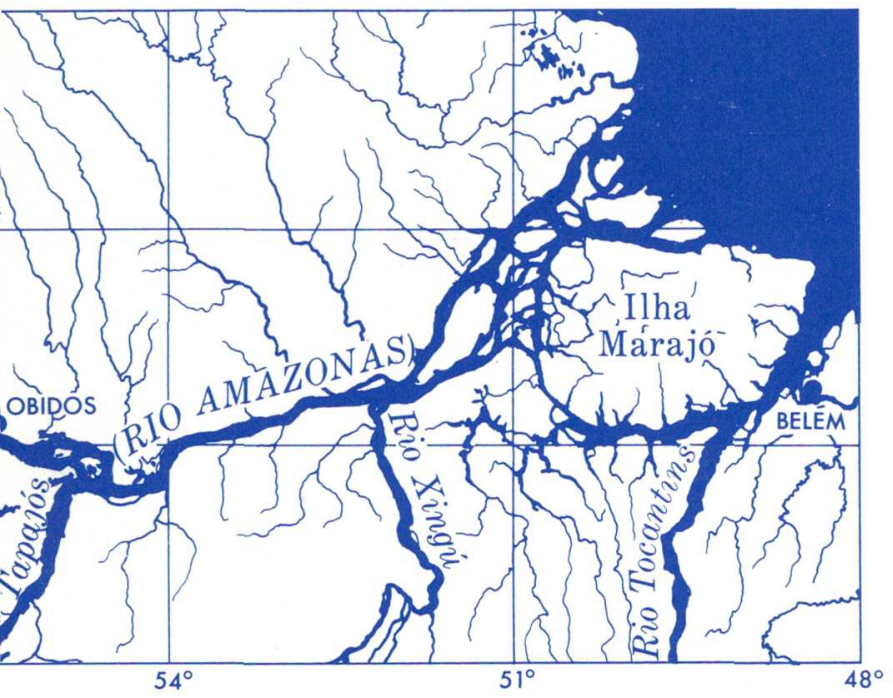




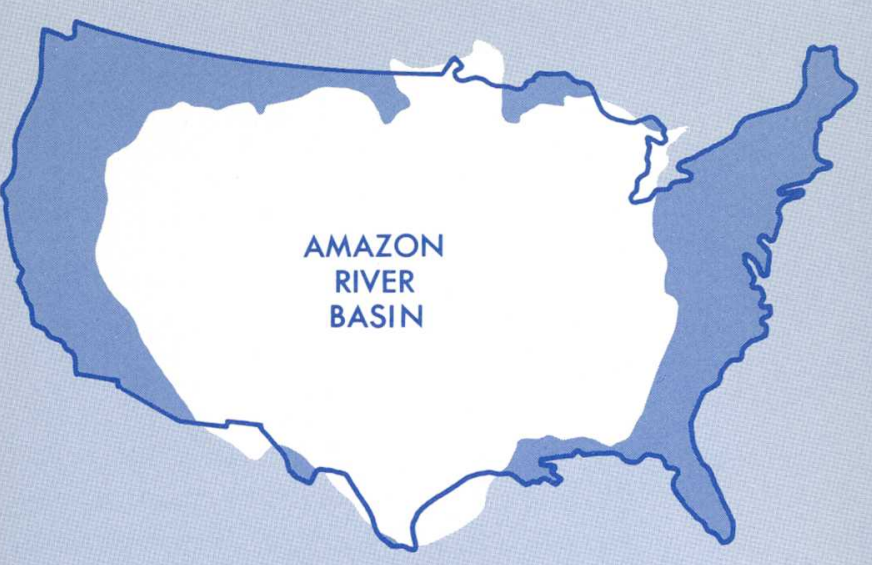

The massive Amazon River Basin covers 2.3 million square miles, an area nearly three-fourths the size of the conterminous United States.

Man and his culture have made small progress in the basin's natural environment. Most settlements are along the river and its tributaries, and they rely chiefly on water transportation. In 1960, the entire population of the basin was estimated to be less than $2 \frac{1}{2}$ million people. Except for periodic exploitation, particularly of the wild rubber trees, the area's interior region has defied rapid development and permanent settlement. Recently, however, a highway was extended through the eastern part of the basin, from the new capital, Brasilia, to Belém, a port city of about 500,000 on the Amazon, in hopes of developing these lands.

The Amazon flows in an unusually straight course

\section{THE RIVER}

from the Andes to the Atlantic Ocean. The mainstream is navigable by ocean-going ships to Iquitos, Peru, about 2,300 miles from the river's mouth. Smaller boats are able to travel even farther upstream, about 450 miles more.

The channel width averages $1 \frac{1 / 2}{2}$ to 3 miles but in some places is 5 to 6 miles wide. The river's depth ranges from 20 to 40 feet near its mouth to more than 300 feet at many places along the lower 900-mile stretch of the river. 
Other large rivers of the world have a significantly larger ratio of high flow to low flow than the Amazon. Its high to low-flow ratio is about 5 to 1 which indicates an uncommonly small difference between flood and low flows. During periods of high flow the river may spill over its flood plain, whereas during periods of low flow drought conditions prevail in parts of the basin.

The chief reason for the relatively small difference between the high and low flows of the Amazon is that the high flows of the two major tributaries, the Rio Negro and Rio Solimões, occur at different periods during the year. As a result, the Amazon has a tendency toward constant flow.

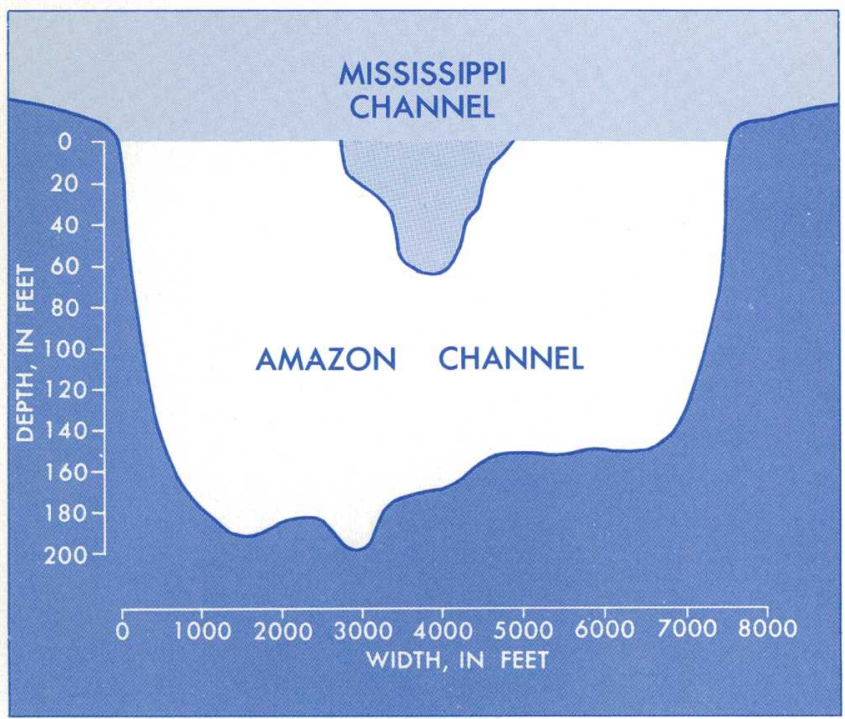

Comparison of channel cross sections of the Amazon River at Obidos and the Mississippi at Vicksburg

A second reason why there is a small difference between high and low flows is that the Amazon has constructed a natural reservoir system. Many large shallow lakes flank the river along the lower parts of its flood plain. These lakes are connected with the river through a maze of small streams and channels that branch off the mainstream and then rejoin it. The lakes maintain about the same water level as the Amazon and serve to regulate the river's flow.

Several of the larger tributaries of the Amazon form lakes that also act as reservoirs, having widths that range from 5 to 10 miles and lengths of as much as 
100 miles. Some of these tributary lakes empty into the mainstream through mouths more than a mile wide, and during periods of high flow the mouth of the Amazon itself gives the appearance of a submerged world with its wide expanse of water interspersed with strips of land.

Not only is the Amazon the largest river on earth, but its waters are among the purest. In some places, water tested by hydrologists of the joint U.S.Brazilian expedition was found to have a chemical purity nearly equivalent to that of distilled water and greater than that of tap water in the United States. One reason for the water's purity is that the heavy rainfall in the basin has almost completely washed the soil of readily soluble minerals that adversely affect the chemical purity of a river. The natural reservoir system also exerts a beneficial influence on the Amazon's water quality by allowing sediment to settle out before the water re-enters the main channel.

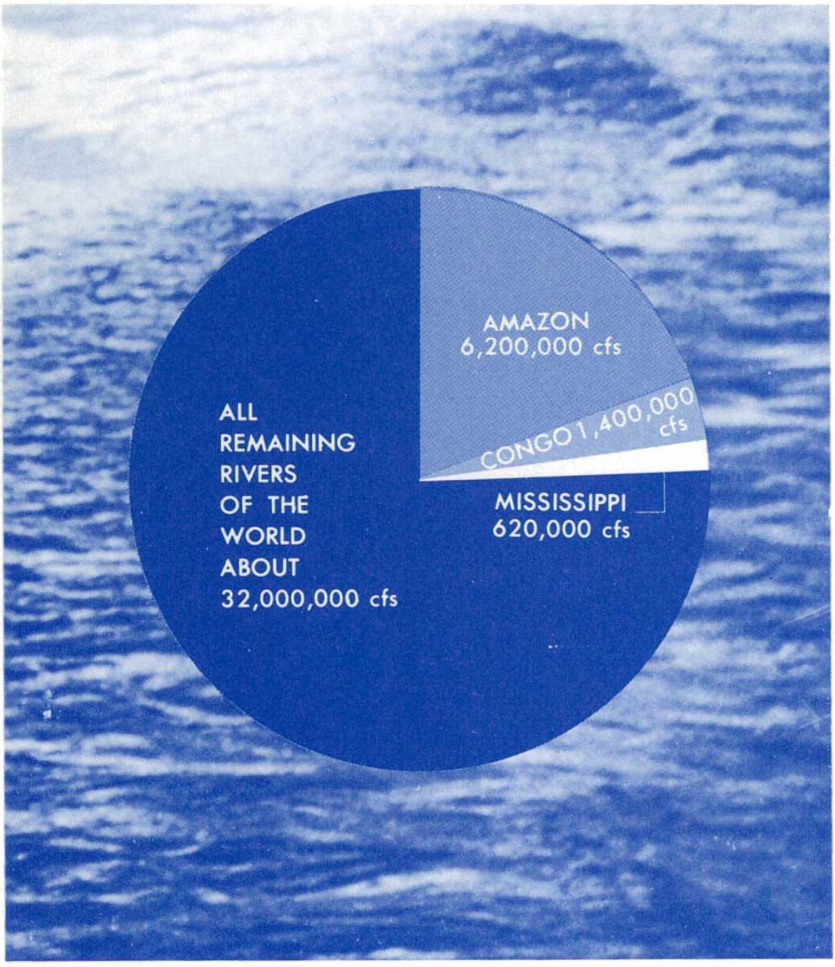

The Amazon's average flow represents 15 percent of all the fresh water discharged into the oceans by all the world's rivers. 


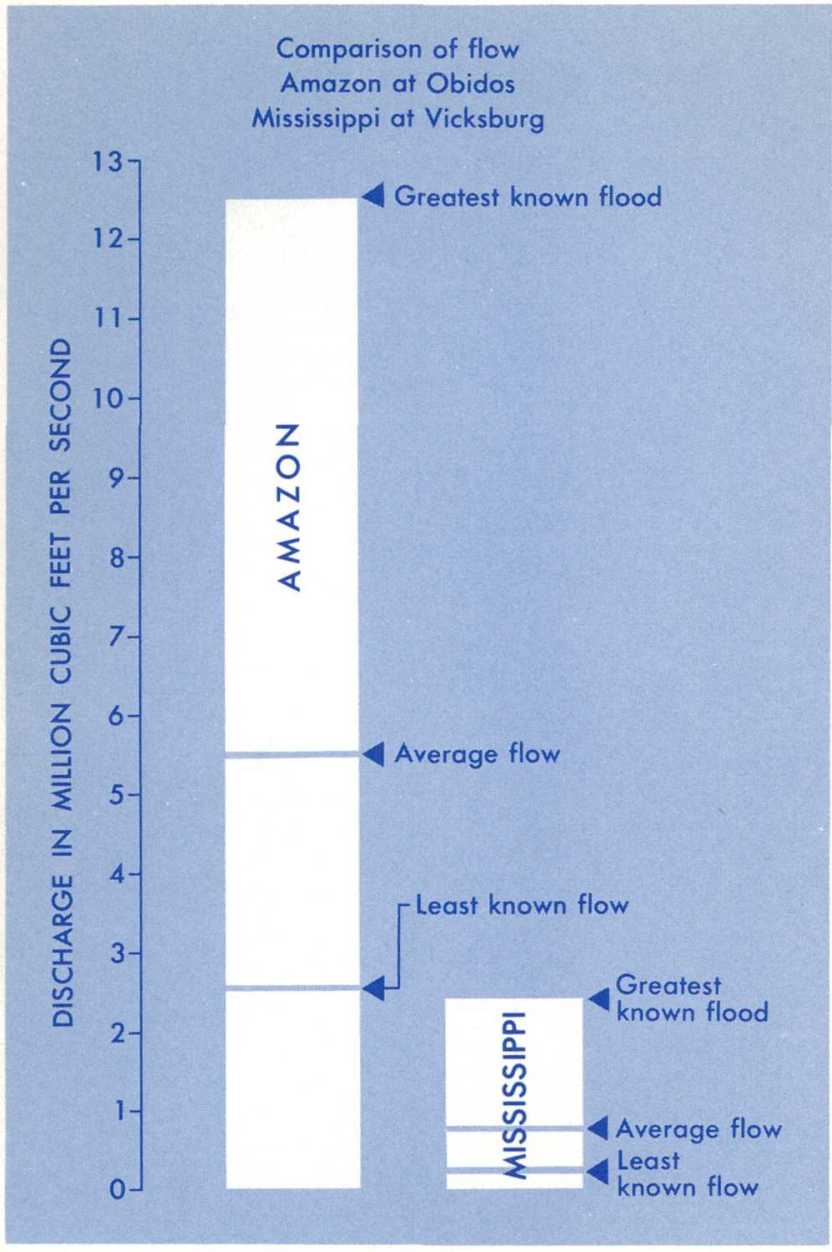

The Amazon's least known flow is larger than the greatest known flood of the Mississippi River.

One of the most notable characteristics of the Amazon is the strong tidal action that affects its water for several hundred miles from its mouth. In addition to this normal tidal effect, a hydraulic phenomenon called a tidal bore (pororoca by Brazilians) sometimes presses upstream at 10 to 15 miles per hour in the river's channel north of Marajó Island, with a breaking wall of water several feet high.

Unlike most rivers, the Amazon does not build a delta. Instead, the river's high rate of discharge transports its small amount of sediment far out to sea, where it is intercepted by ocean currents and deposited along the coast of northern Brazil and the Guianas. 

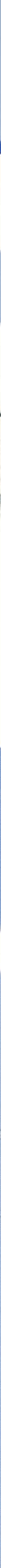


\section{CONDUCTING INVESTIGATIONS}

The joint U.S.-Brazilian scientific team carried out investigations in July 1963 during the Amazon's period of high flow, in November 1963 during its low flow, and in August 1964 during a period of intermediate flow.

The primary objectives of the expedition were to measure the discharge of water, dissolved solids, and suspended sediments of the world's largest river, and to substantiate theories on river behavior that were based on data gathered from the comparatively small rivers in the United States. A secondary objective of the teams' work was to provide precise data on the Amazon to scientists studying the massive transport of dissolved solids and sediments from the continents to the oceans. The lack of data for discharge and dissolved solids of the Amazon had seriously hampered the work of these scientists in computing the a mount of dissolved solids carried by the earth's rivers into the seas.

Hydrologists in the United States generally measure rivers from fixed platforms such as bridges, and from cars hung from cables strung across river channels. Because the Amazon lacks such structures, a Brazilian Navy vessel was used as a floating work platform. The expedition assembled at Belém, where the vessel was outfitted with a boom and an electrically driven winch that lowered a current meter, sounding weight, sediment sampler, and other equipment to a desired depth in the river. Measurements of distance from ship to shore during the process of measuring the discharge were made with a modern electronic instrument-the Tellurometer. A theodolite (a surveying instrument used to measure horizontal angles) located on shore at one end of the river cross section was used to orient the ship on the section and measure the ship's upstream-downstream deviation from the section during observations.

Measuring the discharge of a river requires deftness and skill-especially from a ship that must fight the restless currents of the Amazon. In measuring the discharge of the river, hydrologists of the team followed the standard Geological Survey procedure of dividing the width of the river into 25 to 30 


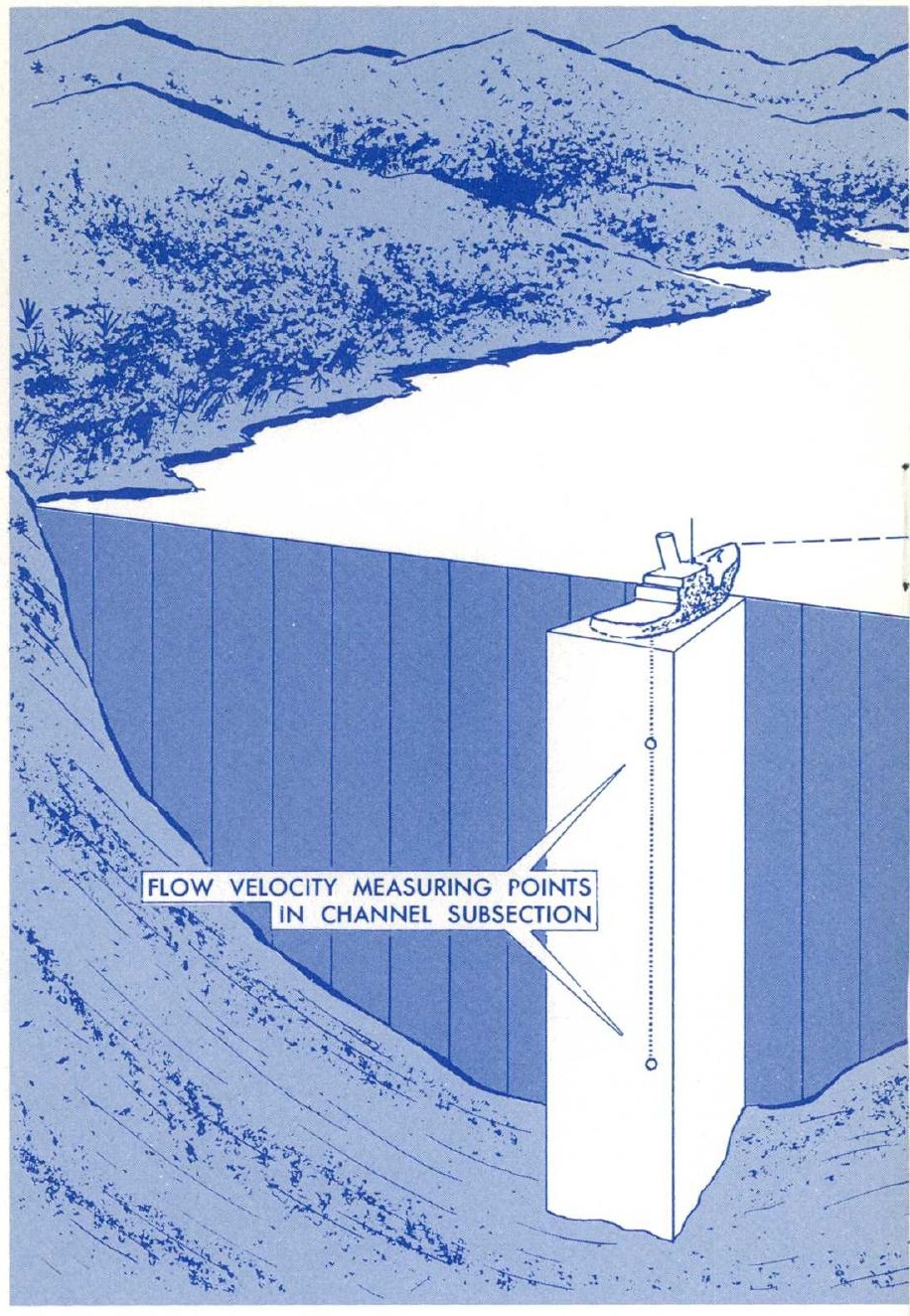

Modern electronic equipment was used to measure each subdivision of the Amazon's cross section.

subsections and measuring the discharge of each. In this way, the sum of the flow in all the subsections is the total flow for the entire cross section of the river. This method minimized errors and produced results of desirable accuracy.

At each point where the Amazon's flow was measured, suspended-sediment samples were taken at several depths, and samples of river-bed material were obtained. As the ship traveled up and down the river, water temperatures were recorded, and samples of water were collected for determining chemical quality. 


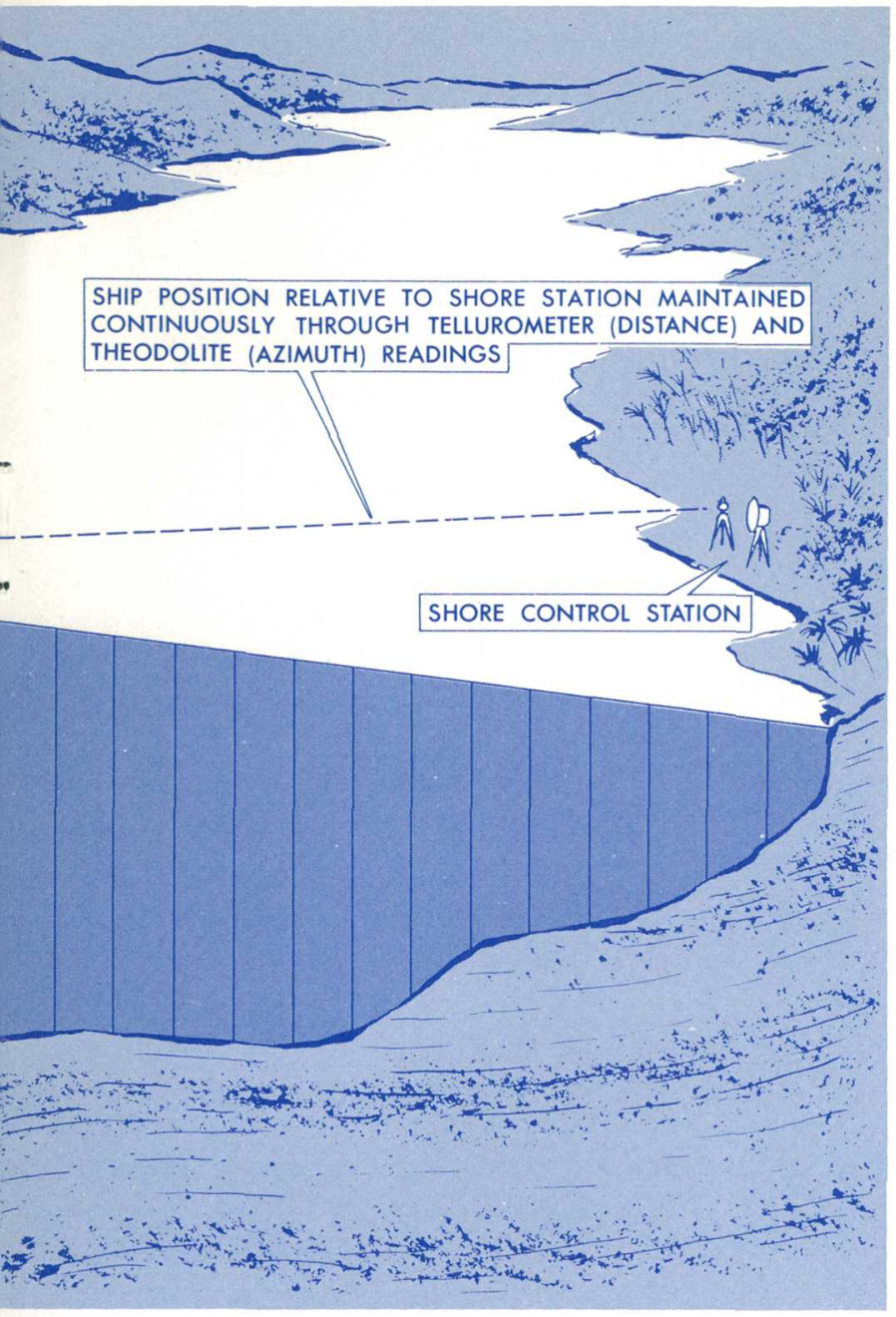

Although it was hard and exacting work, the expedition provided earth scientists and geographers with precise hydrologic information about the Amazon for the first time in history. New data made previous estimates of the Amazon's water resources obsolete. The measured velocities, depths, and widths of this largest river substantiated theories that had been based previously on data collected only on small rivers of the United States. Further, the expedition served to close a gap in hydrologic knowledge that had existed in the library of world hydrology and in doing so provided another increment to man's knowledge of his planet. 


\section{FACTS ABOUT THE AMAZON RIVER}

The 1963-64 hydrologic investigations of the Amazon River revealed:

- The Amazon is the mightiest river on earth; it drains a basin of 2.3 million square miles and discharges almost 3 billion gallons of water per minute at its mouth.

- The river's discharge is over 4 times that of the Congo River and 10 times that of the Mississippi River.

- Measurements of the expedition indicate an average flow of $5 \frac{1}{2}$ million cubic feet per second (cfs) at Obidos, Brazil (about 400 miles upstream from the river's mouth), and an average flow of slightly over 6 million cfs from the mouth of the river into the Atlantic. By comparison, the Mississippi River has an average flow of 560,000 cfs at Vicksburg, Mississippi, and an average flow of 620,000 cfs into the Gulf of Mexico.

- The flow of the river at Obidos was measured at $7,640,000 \mathrm{cfs}$ in July 1963 (high stage), $2,560,000$ cfs in November 1963 (low stage), and $5,810,000 \mathrm{cfs}$ in August 1964 (intermediate stage).

-At least 10 places along the 500-mile stretch between the mouth and Obidos were found to have depths of 300 feet or more, thus revealing that the bed of the river is well below sea level.

- The Amazon is one of the cleanest rivers on earth; its chemical purity is near that of distilled water-better than that of most public water supplies in the United States.

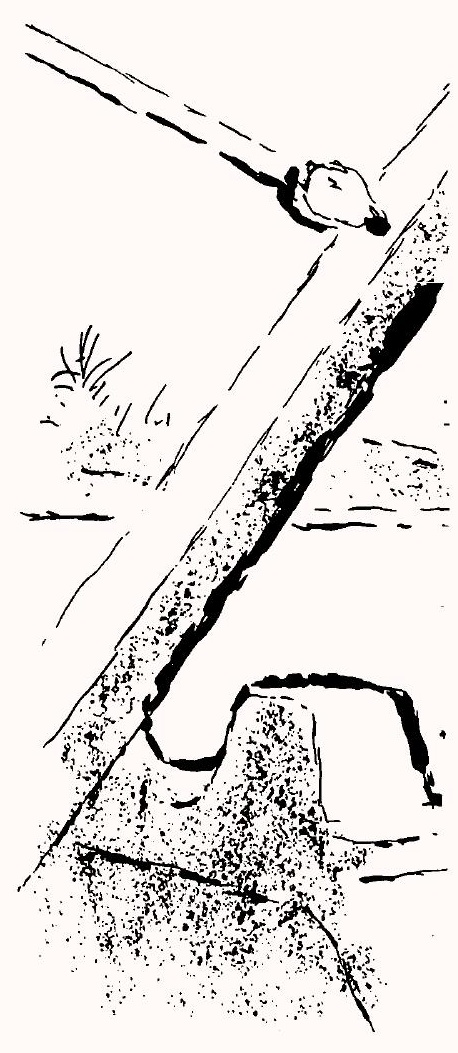


-For long reaches of the river, the bed of the Amazon was found to be a series of moving and rippling sand dunes. Beneath the sand layer is a dense gray clay.

- The year-around water temperature of the Amazon river between Belém and Manaus ranges from $84^{\circ} \mathrm{F}$ to $86^{\circ} \mathrm{F}$. The temperature profiles taken from the surface to the bottom show that mixing of the river by turbulence maintains a constant temperature throughout the river's depth.

-Current-meter observations show uniform distribution of velocities at each measured cross section.

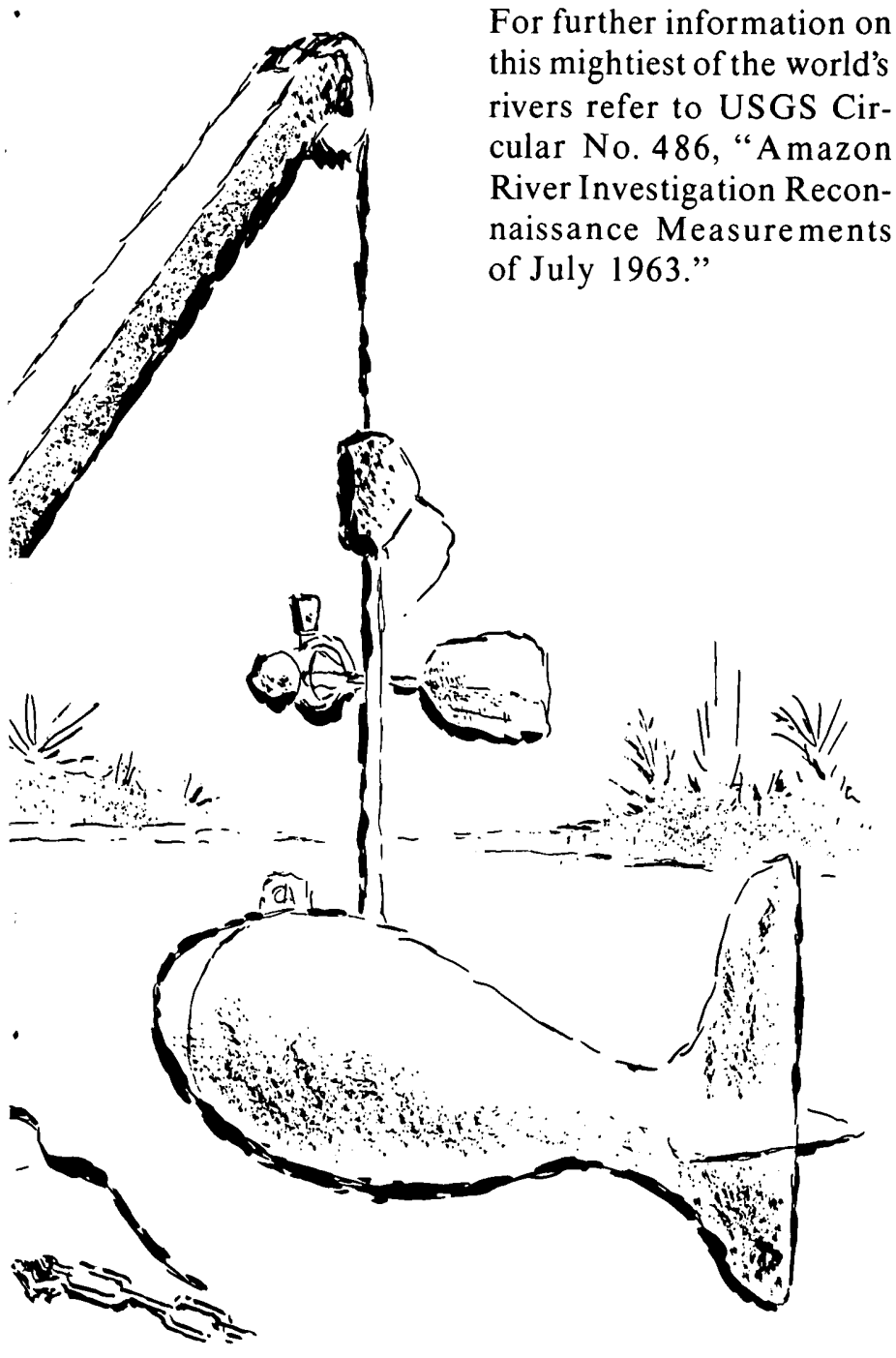


